Full Length Article

\title{
Characterization of pore structures and gas transport characteristics of Longmaxi shale
}

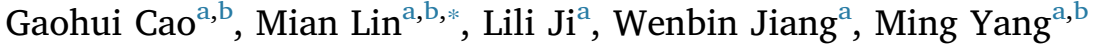 \\ ${ }^{a}$ Institute of Mechanics, Chinese Academy of Sciences, Beijing 100190, China \\ ${ }^{\mathrm{b}}$ School of Engineering Science, University of Chinese Academy of Sciences, Beijing 100049, China
}

\section{A R T I C L E I N F O}

\section{Keywords:}

Shale

Pore structure

Anisotropic permeability

Longmaxi Formation

\begin{abstract}
A B S T R A C T
Multiscale pore structures of shale conjunctionally determine the gas storage and transport properties of gas shale reservoirs. To investigate the complex pore structures and gas transport in the ultra-tight porous media, a combination of petrophysical and scanning measurements is adopted in this study. Five shale samples of the main productive layers from four wells (Long $1_{1}$ sub-members of Longmaxi Formation) in southeast Sichuan Basin, China are analyzed. Based on scanning electron microscope (SEM) image, different types of organic pores and inorganic pores are quantitatively analyzed. A method for identification of organic and inorganic pores from SEM images is developed. And a comparison between the pores identified from SEM and gas adsorption $\left(\mathrm{N}_{2}\right.$ and $\mathrm{CO}_{2}$ adsorption) is conducted. Results show that the main part of inorganic pores are mesopores, and the organic pore size distributions tend to be lognormal with the peak pore size from $10 \mathrm{~nm}$ to $30 \mathrm{~nm}$. Results also show that the gas storage space obtained by SEM is several times to several tens of times larger than that obtained by gas adsorption method. The permeability of OM and shale cores is also compared. The permeability is strongly anisotropic and all those samples show a significant non-Darcy effect. Finally, the relationship between the pore structures and gas transport behavior is studied, and the high quality shale samples are identified considering their gas storage and transport behaviors.
\end{abstract}

\section{Introduction}

Shale gas, generated by the thermal evolution of organic matters $(\mathrm{OM})$ and constrained within the ultra-tight shale, has played an increasingly important role in the North American energy industry in recent years and have gradually become a key component of the world energy supply [1]. In shale gas reservoirs, gas storage and transport has proven a complex behavior in a multiscale pore structure system $[2,3]$.

As a new and abundant energy resource, shale gas is mainly stored in shale reservoirs as free gas in pores and fractures and adsorbed gas on the surface of pores, as well as a small amount of dissolved gas [4]. Due to various gas occurrence in shale formations, its producibility is strongly related to the pore spaces and their connectivity, which indicates the importance of the study on pore structures for sustainable shale resource development [5]. According to the definition of International Union of Pure and Applied Chemistry (IUPAC) [6], pores in shale can be classified into three groups: macropores $(>50 \mathrm{~nm}$ ), mesopores $(2-50 \mathrm{~nm})$ and micropores $(<2 \mathrm{~nm})$. The amount of free gas is thought to correlate well to the volume of meso- and macropores, which account for most of the absolute pore volume. Adsorbed gas has a much higher (heterogeneous) density than free gas at the same temperature and pressure and accounts for most of the gas in micro- and mesopores, which is commonly estimated by high pressure methane adsorption isotherms [7]. Pore structure is one of the major factors that controls the gas capacity and transport and therefore is the key element in shale gas formation characterization and potential assessment [8].

For the transport characteristics, in shale gas reservoirs, gas flows in a multiscale transport system $[2,3]$. Transport in gas shale is quite more difficult than the conventional reservoirs as its richness in nanopores. And the strong heterogeneity between the pores of organic matter $(\mathrm{OM})$, inorganic matter (IOM) and fractures also adds significant complexities into the multiscale problem [9]. Using apparent permeability function in shale is a convenient way: in 2009, Javadpour introduced an apparent permeability term that includes the complexity of flow in nanopores (viscous flow, slip flow and Knudsen diffusion) [10]. Tian et al. [11] calculated methane transport through nanopores using molecular dynamics (MD) simulation and firstly confirm the reliability of the Javadpour's formula based on direct molecular simulation. After Javadpour, plenty of researchers have proposed different equations to account for pore surface roughness, transition flow, adsorption,

\footnotetext{
* Corresponding author.

E-mail address: linmian@imech.ac.cn (M. Lin).
} 
effective stress $[1,3,12-14]$. On the other hand, using laboratory measurements to get the permeability of shale is another general method [15-17]. Laboratory measurements can obtain the permeability of shale core directly. Permeability is commonly measured using a triaxial cell and anisotropic permeability is often using subcored cylindrical samples from a recovered core. However, the sample's heterogeneity can significantly affect the test results. This shortcoming was avoided in a recent work through the introduction of cubic samples [16]. Results also show that the anisotropic permeability has a large impact on gas production and should be routinely measured.

In order to describe the complex pore structure and gas transport in shale, various techniques have been borrowed from material science to illustrate the complexity of pore networks in shales. Porosity can be determined by helium pycnometry, while surface area and pore size distribution can be calculated from $\mathrm{N}_{2} / \mathrm{CO}_{2}$ adsorption. Pore structures can also be directly measured by 3D physical construction through Xray computed tomography (e.g., Micro-CT and Nano-CT) or 2D images such as SEM [13,18-21]. Although our knowledge of the pore network in shales is evolving, a deeper understanding of gas storage and transport mechanisms is required to better assess the economic feasibility of, and to reduce the risks of gas exploration [22]. However, though the advanced imaging techniques can get the pores in shale, few studies quantitatively analyzed the organic and inorganic pores in shale and quantitatively compared the pores obtained from images and gas adsorption. Moreover, the research on the relationships between the pore properties and anisotropic permeability of shale is also lacking. The main aims of this study are quantitatively analyzing the pore characteristics and transport properties of Longmaxi shale based on a combination of petrophysical and scanning measurements, and then studying their relationships and identifying the high quality shale reservoirs.

\section{Samples and experiments}

\subsection{Geological setting and samples}

The Lower Silurian Longmaxi Formation shale is widespread in the Sichuan Basin and the adjacent fold-thrust belts, and is regarded as the most important marine shale gas play in south China [24]. Lower Silurian Longmaxi Formation was deposited in the shelf and intra-shelf low foreland setting with a thickness of 50-600 m, and surrounded by three uplifts including Qianzhong uplift in southwestern, Chuanzhong uplift in northwestern and Jiannan uplift in southeastern [25]. The lithology of the Lower Silurian Longmaxi Formation in the Sichuan Basin, China is mainly the marine organic-rich and quartz-rich siliceous shale. The bottom of the formation is black and grayish-black graptolite rich shale, which is distinct from the lithology on the upper of the formation, dark gray silty shale unequal interbedded with dark gray argillaceous limestone and siltstone laminaes [26-28]. The dominant high-quality shale in Longmaxi Formation of the study area is the lower part of the Longmaxi Formation. The favorable targets of Longmaxi shale gas exploration are identified by synthesizing the following information: the total organic carbon (TOC), thickness of Longmaxi shale, thermal maturity and dip angle of the stratum in Feng et al. [23], as shown in Fig. 1. From Fig. 1, it is obvious that even in those favorable targets, the burial depths can be quite different. We collected five different shale samples of the main productive layers (Long $1_{1}$ sub-members of Longmaxi Formation) from four wells (Well A, B, C, D), the locations of the wells are also shown in Fig. 1. Those samples are from the favorable shale gas zone in Fig. 1. Well C is located in the center of Sichuan Basin. And other wells are in the basin peripheral which have more complex geological structures. In this study, sample 1, 2, 3 are from Well A, B, C, Sample 4 and 5 are from Well D. Their burial depths are about $1100 \mathrm{~m}, 2510 \mathrm{~m}, 3700 \mathrm{~m}, 2518 \mathrm{~m}$ and $2520 \mathrm{~m}$.

A series of experiments is carried out on the collected samples, including helium expansion for porosity, energy dispersive X-ray spectrum (EDS) analysis for mineralogical compositions; SEM for properties of pores in $\mathrm{OM}$ and $\mathrm{IOM} ; \mathrm{N}_{2}$ and $\mathrm{CO}_{2}$ adsorptions for pore size distributions; high-pressure $\mathrm{CH}_{4}$ adsorption for Langmuir coefficients; pulse-decay permeability measurement for anisotropic permeability.

\subsection{Experiments and simulations}

\subsubsection{Helium porosity measurement}

The porosity of the shale samples was measured using a gas expansion method with helium (He). The method relies on the ideal gas law where the pressure times the volume for a system is constant. The rock was sealed in a container of known volume and then the grain volume was measured. The small size of He molecule means that it can penetrate even the micropores. The bulk volume of the rock was determined using Archimedes Method with ethyl alcohol. The grain volume and bulk volume can be then used to calculate the He porosity. The method is a rapid technique and can leave the sample available for further tests.

\subsubsection{SEM and EDS measurements}

SEM was conducted on an environmental scanning electron microscope to observe the shale pore structures. Argon ion polishing technology was utilized for the surface of the samples. SEM measurements are conducted on a Zeiss-Merlin rock mineralogy analysis machine at $1.2 \mathrm{kV}$. The SEM images with the size of $400 \times 400 \mu \mathrm{m}^{2}$ and the maximum resolution of $4 \mathrm{~nm}$ are obtained. Through the SEM images, the components of the shale samples were identified as follows: organic pores, inorganic pores and content of OM blocks. The mineralogy of the samples was also analyzed using the same equipment as SEM through EDS with the size of $400 \times 400 \mu \mathrm{m}^{2}$ and the maximum resolution of $4 \mathrm{~nm}$.

SEM scanning can obtain the high-precise surface topography gray images. After the scanning measurement, a method for identification of organic and inorganic pores from SEM images is developed. Using the SEM with the size of $400 \times 400 \mu \mathrm{m}^{2}$, the size of representative element surface (RES) of the shale sample is calculated [29]. The heterogeneity is relatively strong in a small area. To calculate the smallest RES, four subdomains of the SEM are chosen from the corners of the image, as shown in Fig. 2. Then the target areas are expanded and the lengths of the subdomains increase. We calculated the average grayscales in the subdomains and the variation of them will diminish gradually as the lengths of the subdomains increase. When the average grayscales reach a platform, the smallest RES is determined. For the five shale sample in this work, after the calculation of RES, the maximum size of smallest RES of the five samples is about $320 \times 320 \mu \mathrm{m}^{2}$, and the minimum size is about $250 \times 250 \mu \mathrm{m}^{2}$. The pore analyses of SEM images are at the smallest RES considering its representation and the computing expense in this study.

In the RES region, the organic and inorganic pores are identified as followings: (1) The whole SEM image is divided into small parts with the size of $4 \times 4 \mu \mathrm{m}^{2}$ and the resolution of $4 \mathrm{~nm}$ for calculation considering the computing expense and computer memory. A median filtering are conducted to reduce the impulse noise. The gray of the target pixel is smoothed using the median gray of its surrounding pixels. (2) Found the gray ranges of pores, OM and IOM in the SEM. There are two gray thresholds for extraction: one is the gray threshold between pores and OM, another is between OM and IOM. As the pores in OM and IOM will have a similar threshold, so it is necessary to separate OM and IOM firstly. (3) The regions of OM and IOM are distinguished according to their different gray ranges. (4) Organic and inorganic pores are then extracted according to their neighbourhood (OM or IOM), respectively, as shown in Fig. 3. As for the pores exist between OM and IOM, we regard them as inorganic pores.

Though SEM gives the image of pore surfaces in 2D, assuming a same pore size distribution of each layer of a 3D cubic core considering 


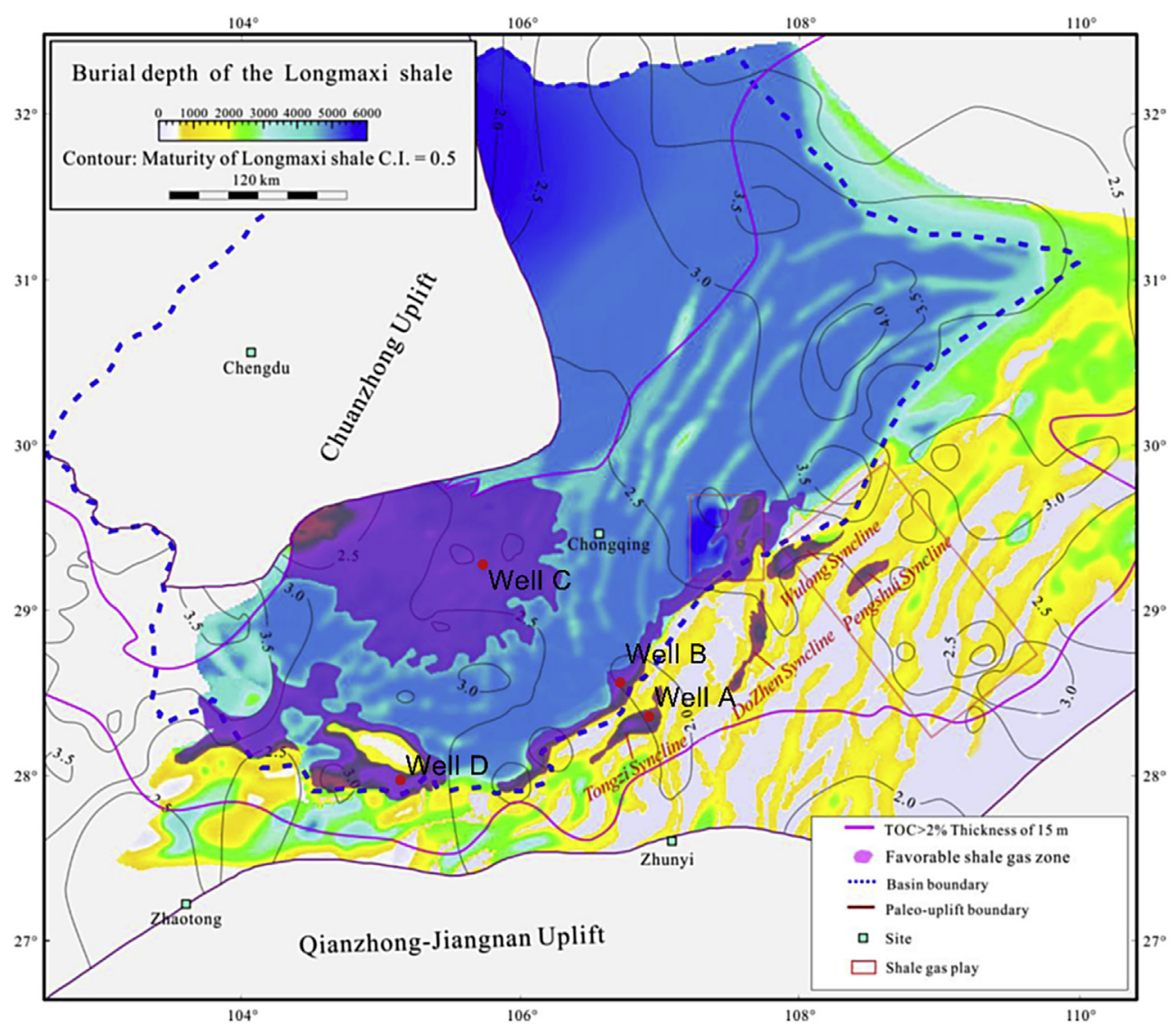

Fig. 1. Illustration of favorable gas zone and the burial depth of Longmaxi shales in the Sichuan basin and the locations of our interesting wells (Well A, B, C, D) (modified after Feng et al. [23]).

the representation of the SEM, it is theoretically feasible to calculate the pore volume per unit mass of shale from it. Based on the results of the extracted components: the OM content, surface porosity and pore size distributions of OM and IOM are then calculated.

\subsubsection{Gas adsorption measurements}

Low-pressure adsorption was performed by using $\mathrm{N}_{2}$ and $\mathrm{CO}_{2}$ as adsorbates. The powder samples with particle size of 100-130 mesh were dried under $140{ }^{\circ} \mathrm{C}$ and degassed for $72 \mathrm{~h}$ before the testing. $\mathrm{N}_{2}$ adsorption isotherms were conducted at $77 \mathrm{~K}$. The relative pressure $(\mathrm{P} /$ $\mathrm{P}_{0}$ ) ranges from 0.01 to $0.995 . \mathrm{CO}_{2}$ adsorption isotherms were conducted at $273 \mathrm{~K}$ with $\mathrm{P} / \mathrm{P}_{0}$ ranges from 0.0003 to 0.03 . The adsorption data were interpreted using nonlocal density function theory (NLDFT) analysis for pore size distribution. High-pressure $\mathrm{CH}_{4}$ adsorption experiments were also carried out using an adsorption isotherm setup based on the volumetric method. $\mathrm{CH}_{4}$ adsorption experiments were conducted at constant temperature of $40{ }^{\circ} \mathrm{C}$. The samples were crushed to powders size ranging from 40 to 150 mesh and were used for adsorption experiments. Then, the Langmuir adsorption isotherm model is used for plotting and estimation of Langmuir coefficients.

\subsubsection{Pulse-decay permeability measurement}

Pulse-decay permeability measurement is a commonly used method for low-permeability rocks for which it is difficult and time consuming to establish steady state measurement. The method involves observing the decline of the pressure gradient between upstream and downstream
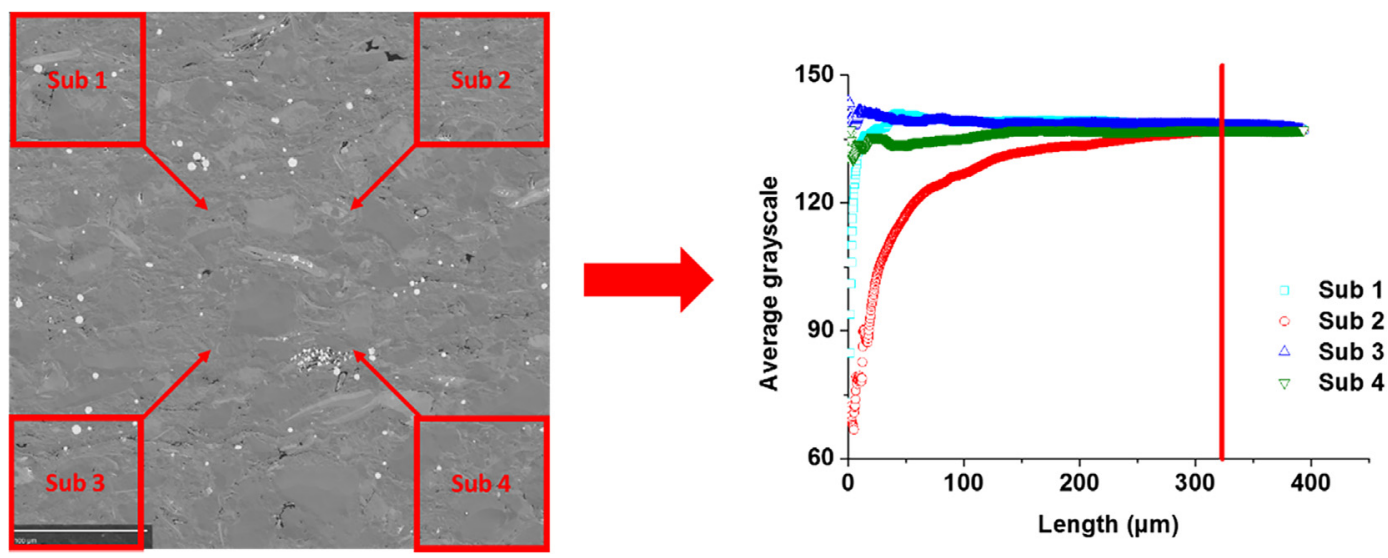

Fig. 2. RES calculation for the SEM image. 


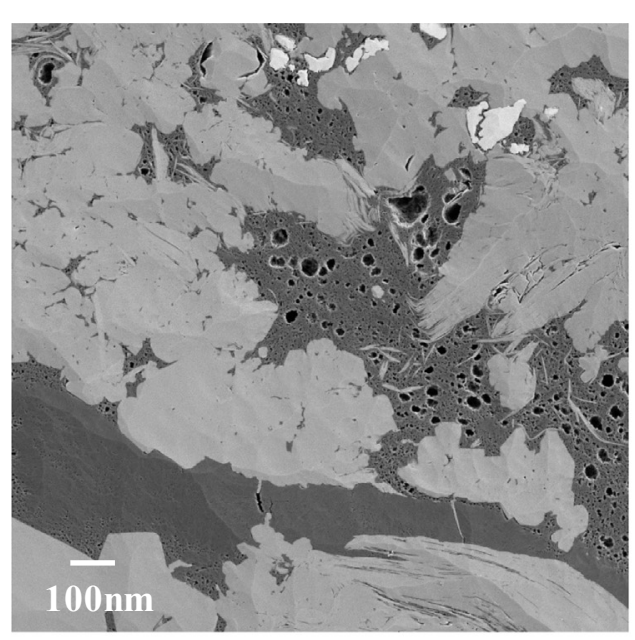

(a)

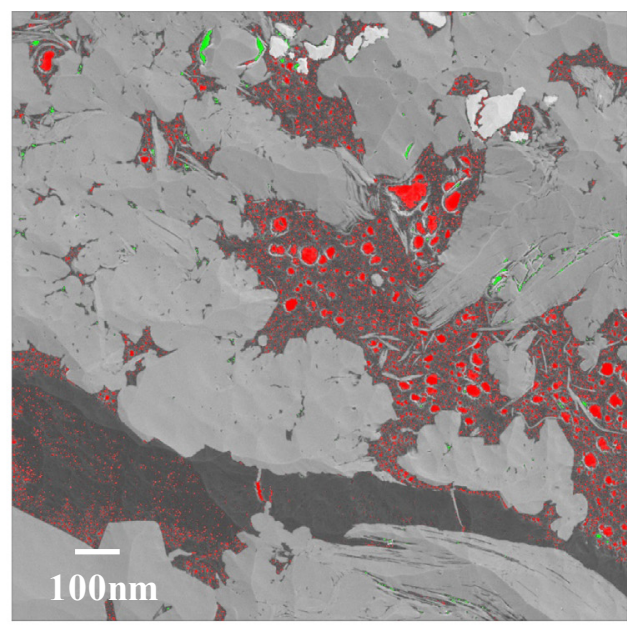

(b)

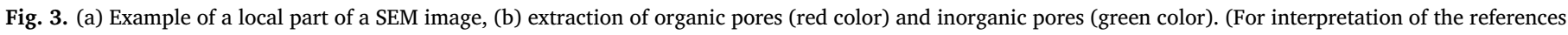
to color in this figure legend, the reader is referred to the web version of this article.)

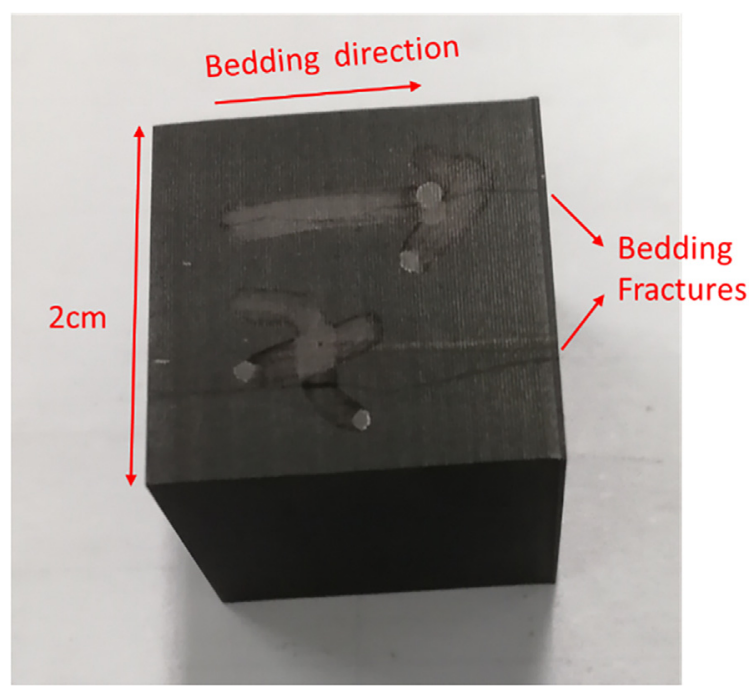

Fig. 4. Cubic shale sample and its bedding fractures.

loaded with an inert gas such as nitrogen or helium. Follow Pan's work [16], a cubic sample and helium gas are adopted in our experiments. A diamond wire saw was used to cut a sample cube from a cylindrical core sample. This cutting is cautious to obtain a pair of parallel planes following the directions of the bedding fractures, as shown in Fig. 4. So both the permeability along the bedding direction and perpendicular to the bedding direction can be measured. After the cubic sample was prepared, a 3D-printed and silica-mode technique was applied to manufacture a membrane to hold the sample and then the pulse-decay permeability measurements are conducted. All the permeability measurements were performed under the temperature of $311 \mathrm{~K}$ and the effective pressure of $3.5 \mathrm{MPa}$.

\section{Pore structure characteristics}

In this section, the pore structures of the samples are analyzed based on imaging measurements and experiments. Pores in shale generally have several different types which have significant influence on the gas transport, such as organic pores and inorganic pores. The different types of pores are studied. Imaging techniques and petrophysical experiments are combined to the quantitative characterization of pores in shale.

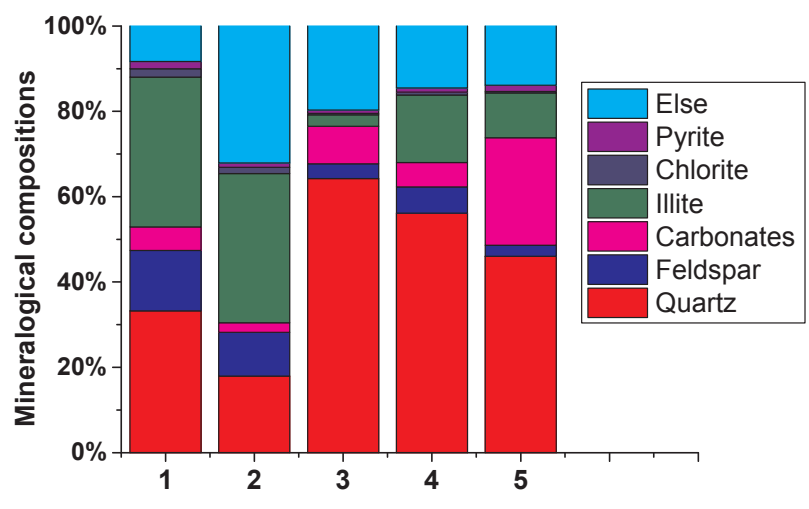

Fig. 5. Mineralogical compositions of all samples.

\subsection{Mineralogy}

The mineralogical compositions of all samples were determined by EDS, as summarized in the stack diagram (Fig. 5). Quartz, feldspar, and clays are present in all samples in varying abundance. All samples except Sample 2 are quartz rich. And Sample 1, 2 and 4 are also enriched in clay. And in the clay, illite is dominant with a small amount of chlorite and there is scarcely any montmorillonite. The quartz contents vary from $17 \%$ to $64 \%$. And the quartz contents of Sample 3, 4 and 5 are similar, which are much higher than Sample 1 and 2. However, the clays of Sample 1 and Sample 2 are in high content with the value of about $36 \%$. Sample 3 has a large amount of quartz of $64 \%$ but quite less clay of $3 \%$. Shales rich in quartz are suitable for hydraulic fracturing and are more likely to be the target for exploration. Moreover, Sample 5 have much carbonate, which is different from the mineral compositions of Sample 1-4.

\subsection{Inorganic pores}

SEM is utilized to examine the inorganic pores. Overall, SEM images (Fig. 6) show that various types of inorganic pores are developed with pore size between several nanometres and several hundred nanometers in the Longmaxi shale samples. According to the occurrences of inorganic pores, they can be grouped into inter-particle (interP) and intraparticle (intraP) pores [30]. The interP pores are distributed between different mineral particles, ranging from soft clay minerals to hard rigid minerals, and mainly have a slit shape. The intraP pores are identified 


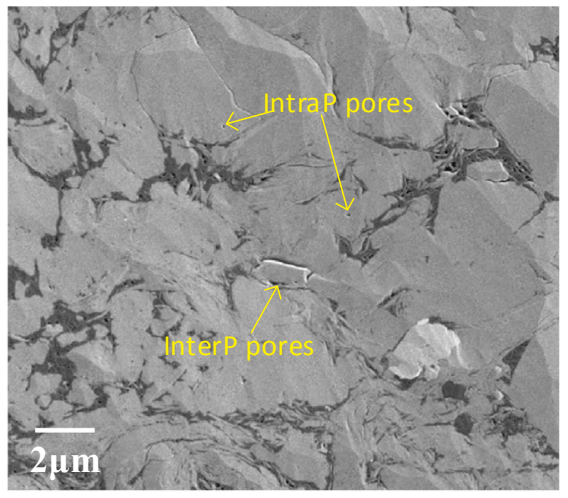

(a)

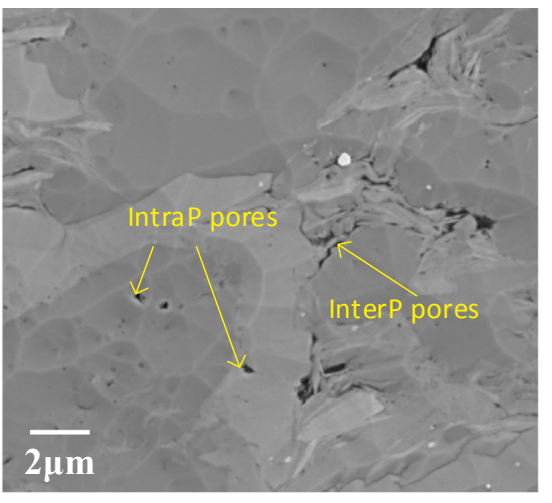

(b)

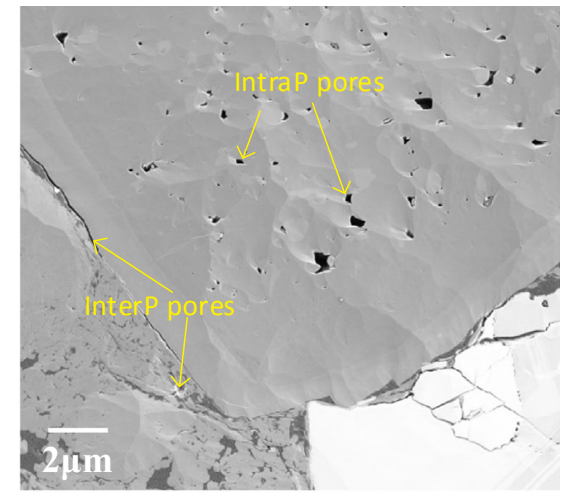

(c)

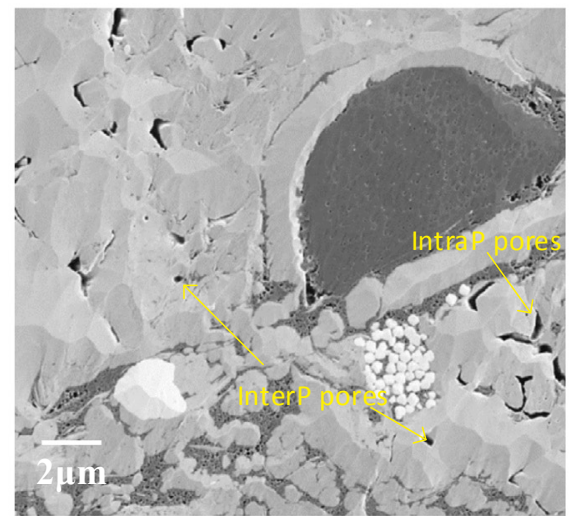

(d)

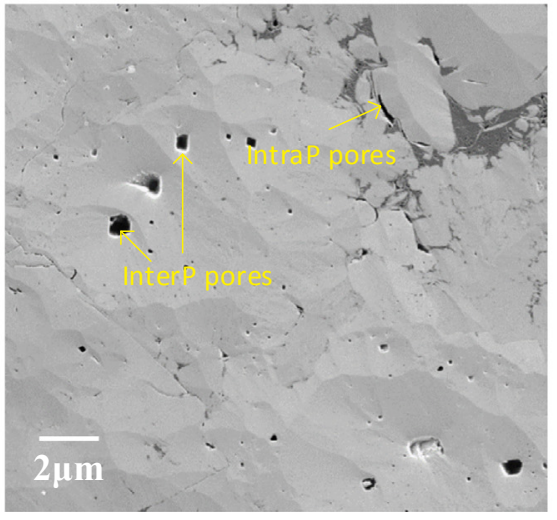

(e)

Fig. 6. Inorganic pores of all samples. (a) Sample 1, (b) Sample 2 and (c) Sample 3, (d) Sample 4 and (e) Sample 5.

within incompletely filled quartz, with polygonal pores.

From the SEM image, the inorganic pore size distributions of those samples are obtained, as shown in Fig. 7. The dv/dD in the y-axis in Fig. 7 is differential pore volume, which means the pore volume in the unit range of pore size and is typically used to characterize pore size distribution. It can be seen that the main parts of the inorganic pores are mesopores. However, there also exists some macropores even larger than $500 \mathrm{~nm}$. The inorganic pore size distributions of Sample 1, 3, 4 and 5 show a peak around $10 \mathrm{~nm}$. For Sample 2, the peak is around $50 \mathrm{~nm}$. The differences between the pore sizes at the peak may because Sample 2 is not enriched in quartz which differs from other samples. Sample 5 has a wide range of pores around the peak, which suggests pores develop in various minerals. The differences between the inorganic pore

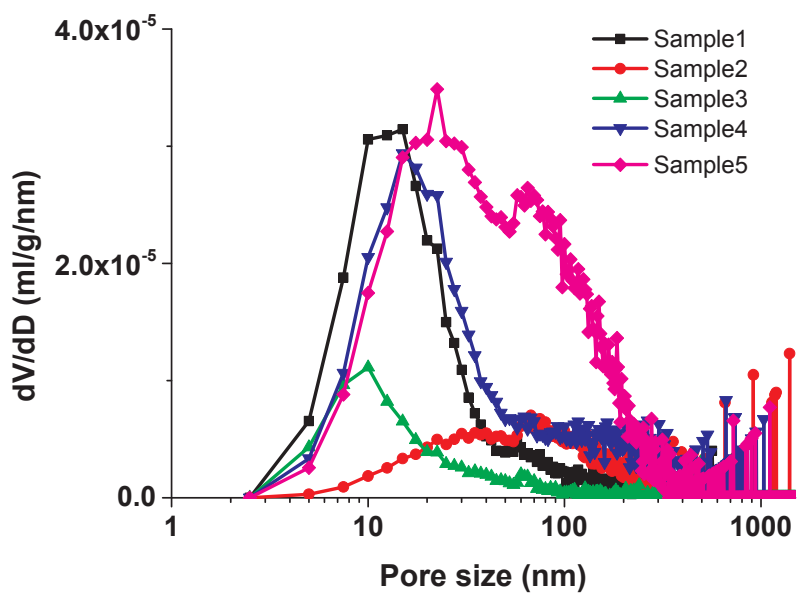

Fig. 7. Inorganic pore size distribution of the samples measured by SEM. size distributions will then influence the transport permeability.

\subsection{Organic pores}

Organic pores are the most ubiquitous pore type in all organic-rich shale [31]. From the SEM images, the organic pores of all samples are analyzed.

Fig. 8 shows that the organic pores are complex in those samples. Sample 1 has three different organic pore types: type 1 has atypic pores with high connectivity; type 2 has alveolate pores; pores in type 3 are dispersive micropores with low porosity. Sample 2 has single organic pore types with spherical to elliptical shapes. Organic pores dominate below $20 \mathrm{~nm}$. Organic pores in Sample 3 have two distinct-different types: one with abundant small pores, another with much bigger pores accompanied with many minerals. Sample 4 has two organic pore types with pleated macropores or mesopores. The organic pore in Sample 5 is dominant by macropores.

From the SEM images, combing the different OM pore types, the organic pore size distributions of those samples are also calculated, as shown in Fig. 9. The distributions tend to be lognormal. And the peak pore sizes are from $10 \mathrm{~nm}$ to $30 \mathrm{~nm}$. Sample 2 has least organic pores in those samples, which can also be seen in Fig. 8d as OM in Sample 2 is very compact. The volume of organic pores in Sample 4 is much greater than the others, with a highest peak around $20 \mathrm{~nm}$. Comparing Figs. 7 and 9, organic pores are more than inorganic pores in mesopore, but less in macropore. And the peak values of $\mathrm{dV} / \mathrm{dD}$ of organic pores are much larger than that of inorganic pores, which suggests organic pores occupy a significantly important proportion in the total pores of shale.

\subsection{Pore size distribution using gas adsorption}

The pore size distribution in shale is also calculated from the $\mathrm{N}_{2}$ and 


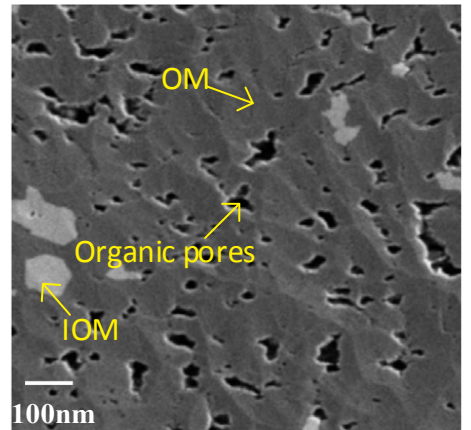

(a)

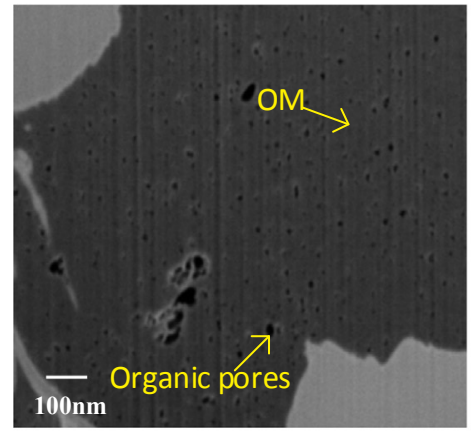

(d)

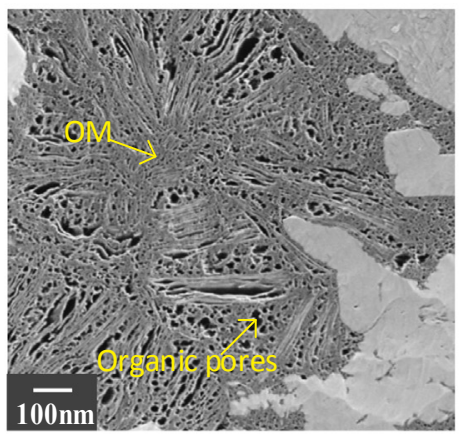

(g)

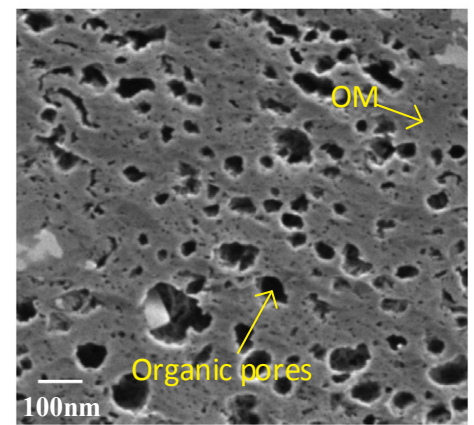

(b)

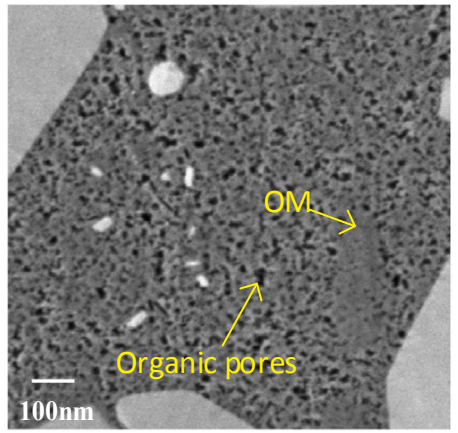

(e)

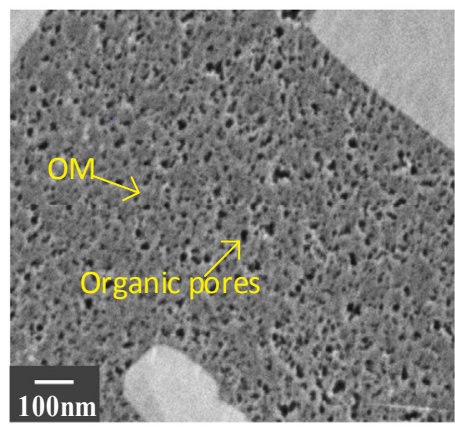

(h)

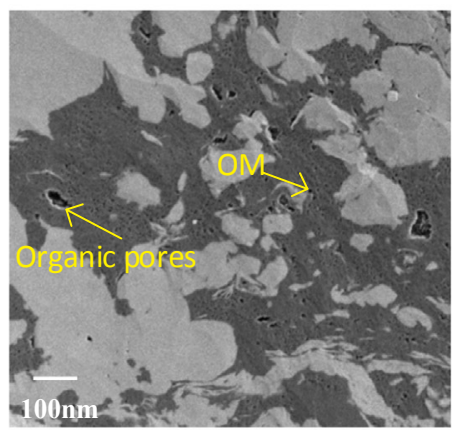

(c)

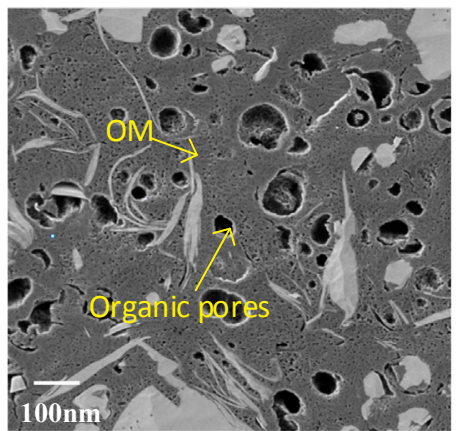

(f)

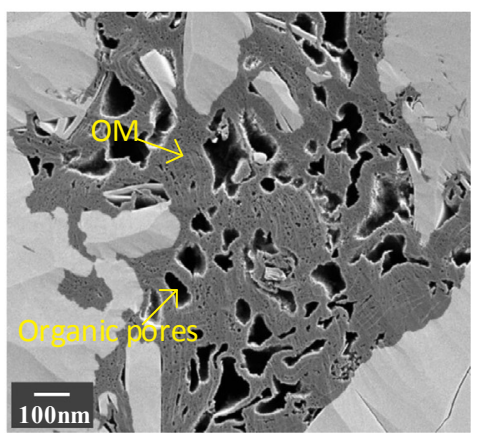

(i)

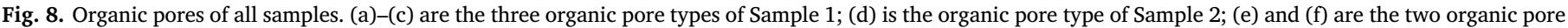
types of Sample 3; (g) and (h) are in Sample 4; (i) is the organic pore type in Sample 5.

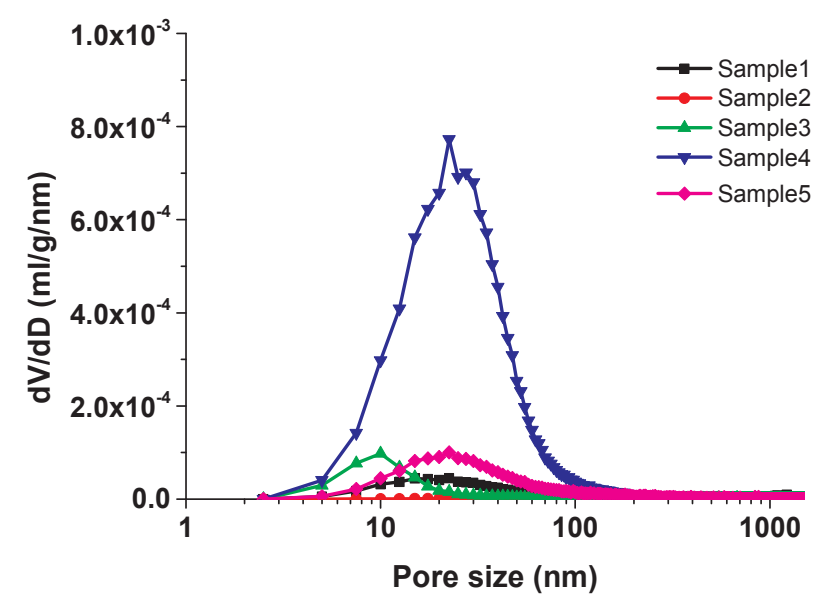

Fig. 9. Organic pore size distribution of the samples measured by SEM.
$\mathrm{CO}_{2}$ adsorption measurements. $\mathrm{N}_{2}$ adsorption provides pore size distributions in the range of $1.7-50 \mathrm{~nm}$, while $\mathrm{CO}_{2}$ adsorption is used for measurements of pores within $1.7 \mathrm{~nm}$. NLDFT is applied to calculate the pore size distribution curves. As illustrated in Fig. 10, all the pore size distributions of those samples are multi-peak functions. And those samples are enriched in micropores. Among those samples, the percentage of micropores in Sample 4 is greater than the others. Differ from other samples, Sample 2 has much more mesopores with several peaks around $20-50 \mathrm{~nm}$.

\subsection{Statistical pore properties}

In this section, the statistical pore properties are analyzed. The parameters of the five samples are listed in Table 1 . He porosity of those samples ranges from $0.3 \%$ to $7.3 \%$. Sample 1 is the most compact sample, while Sample 5 has a large gas storage space. From SEM, the volumetric OM content is calculated. Sample 3 and 4 have a high OM content, while Sample 2 and Sample 5 mainly consist of inorganic minerals. The surface porosity of OM is quite higher than that of IOM. Pores in OM forms pore networks in which large amount of free gas and adsorbed gas stores. However, the total surface porosity is close to the 

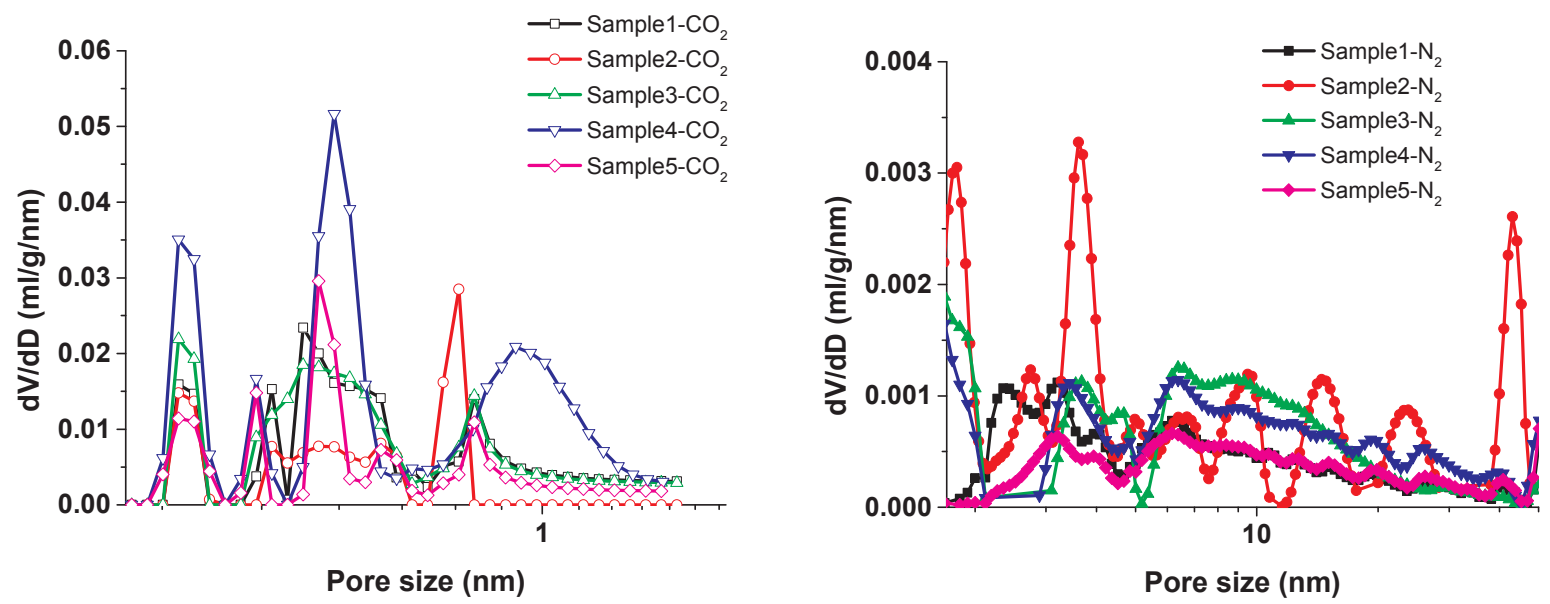

Fig. 10. Pore size distribution of the samples measured by $\mathrm{N}_{2}$ and $\mathrm{CO}_{2}$ adsorption.

surface porosity of IOM, as IOM is the major component. Average pore sizes of OM range from $14 \mathrm{~nm}$ to $42 \mathrm{~nm}$, while in IOM, pore sizes range from $15 \mathrm{~nm}$ to $57 \mathrm{~nm}$. This is because more macropores exist in IOM. The Langmuir volume $\left(\mathrm{V}_{\mathrm{L}}\right)$ and Langmuir pressure $\left(\mathrm{p}_{\mathrm{L}}\right)$ are measured by high-pressure methane adsorption. Comparing the volumetric OM content and Langmuir volume, it is shown that the adsorbed gas in shale will increase basically as OM content increases.

\subsection{Relationships between pore volume and pore surface}

The relationship between the pore volumes and pore surfaces is studied. Results show that both the total pore volume and pore volume of micropores increased with the increase of Brunauer-Emmett-Teller (BET) specific surface area, as shown in Figs. 11 and 12. There is a good correlation between the micropore volumes and BET specific surface areas of the samples with the determination coefficient, $\mathrm{R}^{2}=0.97$. This can be explained as the specific surface is mainly controlled by the micropores. The correlation between the total pore volumes and BET specific surface areas of the samples is also good with $R^{2}=0.85$ but worse than that between the micropore volume and BET specific surface area as the total pores will also be influenced by the macropores. However, there is almost no correlation between He porosity and BET specific surface area as shown in Fig. 13, which is because porosity is mainly controlled by mesopores and macropores while specific surface area is mainly controlled by micropores.

\subsection{Comparisons of pore properties obtained from SEM and gas adsorption}

We compare the pore properties obtained from SEM and gas adsorption, as listed in Table 2. Some parameters cannot be measured simultaneously by the two methods, for example, SEM can obtain the surface porosity, while gas adsorption can measure the micropore volume. Total pore volumes from SEM are much bigger than that from gas adsorption, while specific surface area from SEM is much less. This phenomenon can be explained as follows: SEM can measure macropores but cannot measure micropores due to its limitation in resolution, and

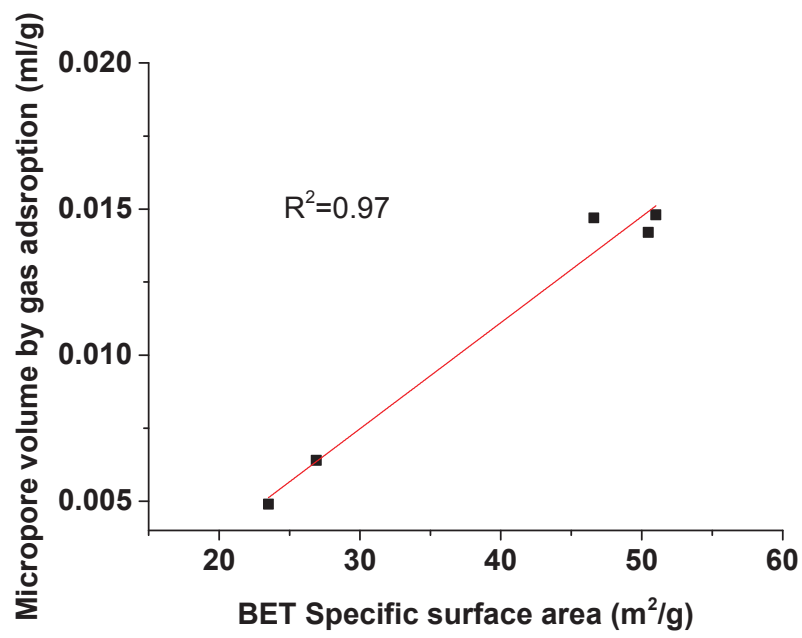

Fig. 11. Relationship between the micropore volumes and BET specific surface areas of the samples.

macropores have bigger volumes while micropores have wider surface. As gas adsorption can hardly measure pores greater than micrometer, average pore sizes from SEM are also bigger than that from gas adsorption.

The pore size distributions measured by the two methods of different samples are also compared. Considering the limitations of SEM and gas adsorption, only the pores from $4 \mathrm{~nm}$ to $50 \mathrm{~nm}$ are compared, as shown in Fig. 14. Comparing the pores in $4 \mathrm{~nm}-50 \mathrm{~nm}$, the results of the two methods are in great difference. The pores measured by gas adsorption have significantly more micropores and mesopores than SEM, while SEM has more macropores. As shown in Fig. 15, for the same pore space, when gas adsorption and SEM identify the same pores, the two methods will have big difference. Gas adsorption identifies the pores from the small pores, as gas firstly fills the small pores and then gradually fills the large pores. For the irregular pores shown in Fig. 15, gas

Table 1

Parameters of the five samples.

\begin{tabular}{|c|c|c|c|c|c|c|c|c|c|}
\hline $\begin{array}{l}\text { Shale } \\
\text { sample }\end{array}$ & He porosity & $\begin{array}{l}\text { Volumetric OM } \\
\text { content }\end{array}$ & $\begin{array}{l}\text { Surface porosity } \\
\text { of OM }\end{array}$ & $\begin{array}{l}\text { Surface porosity } \\
\text { of IOM }\end{array}$ & $\begin{array}{l}\text { Total surface } \\
\text { porosity }\end{array}$ & $\begin{array}{l}\text { Average pore size of } \\
\text { OM }(n m)\end{array}$ & $\begin{array}{l}\text { Average pore size of } \\
\text { IOM }(\mathrm{nm})\end{array}$ & $\mathrm{V}_{\mathrm{L}}\left(\mathrm{m}^{3} / \mathrm{t}\right)$ & $\mathrm{p}_{\mathrm{L}}(\mathrm{MPa})$ \\
\hline Sample 1 & $0.3 \%$ & $5.4 \%$ & $21.7 \%$ & $0.6 \%$ & $1.7 \%$ & 20 & 27 & 3.26 & 2.25 \\
\hline Sample 2 & $1.7 \%$ & $2.3 \%$ & $3.0 \%$ & $0.8 \%$ & $0.9 \%$ & 42 & 57 & 1.58 & 4.65 \\
\hline Sample 3 & $5.5 \%$ & $13.7 \%$ & $3.0 \%$ & $0.2 \%$ & $0.5 \%$ & 14 & 15 & 5.19 & 2.29 \\
\hline Sample 4 & $4.2 \%$ & $16.8 \%$ & $13.9 \%$ & $0.2 \%$ & $2.5 \%$ & 32 & 28 & 3.76 & 2.32 \\
\hline Sample 5 & $7.3 \%$ & $2.1 \%$ & $10.6 \%$ & $0.4 \%$ & $0.8 \%$ & 34 & 41 & 2.28 & 2.41 \\
\hline
\end{tabular}




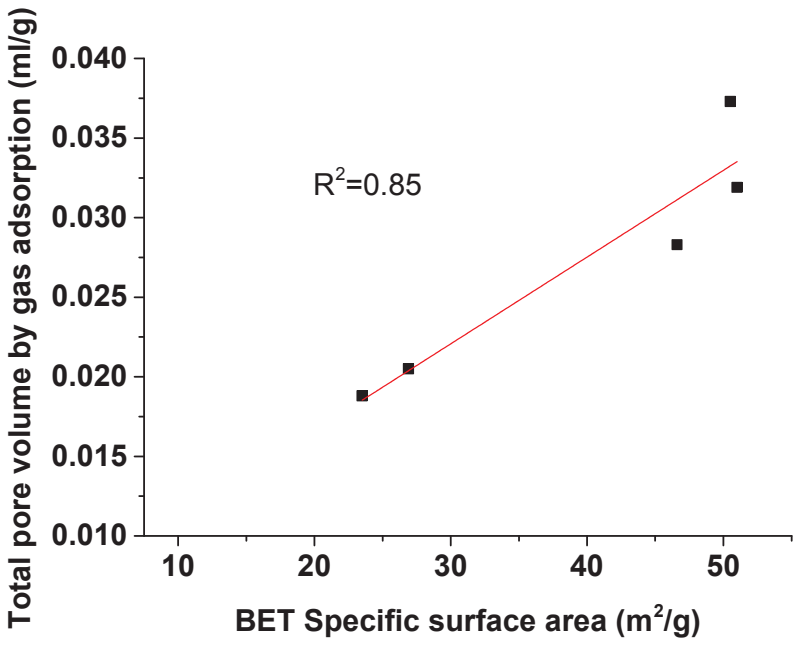

Fig. 12. Relationship between the total pore volumes and BET specific surface areas of the samples.

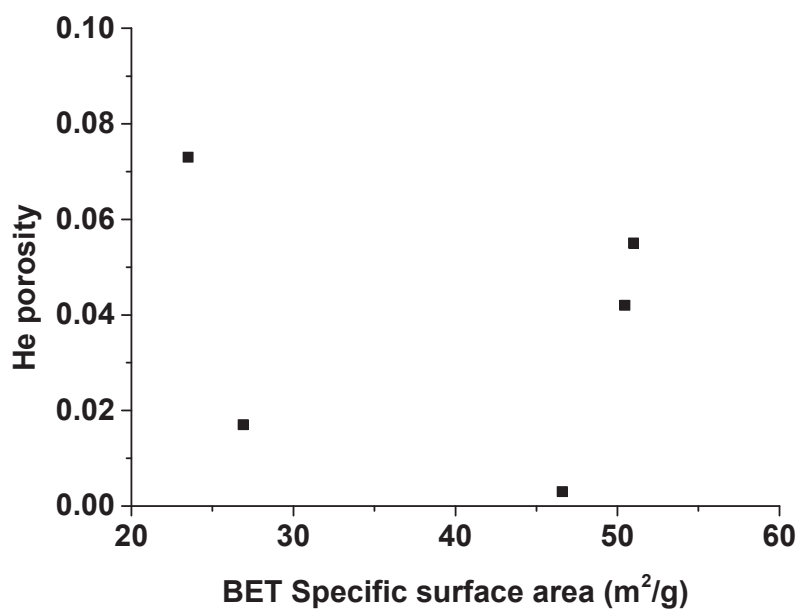

Fig. 13. Relationship between He porosity and BET specific surface areas of the samples.

adsorption identifies a series of small pores; while the SEM identifies a complex pore with a relatively big equivalent radius of the pore space. This distinction between pore definitions results in more micropores but less macropores in gas adsorption than in SEM.

We also compare the gas volumes between gas adsorption and SEM, considering that although there are differences in the definition of complex pores, for an irregular pore, whether defining it as a series of small pores or one large pore, the pore volume remains unchanged. Therefore, the total pore volumes measured by gas adsorption and SEM are further compared, as shown in Fig. 16. The total pore volume obtained by SEM is found to be several times to several tens of times larger than that obtained by gas adsorption method.

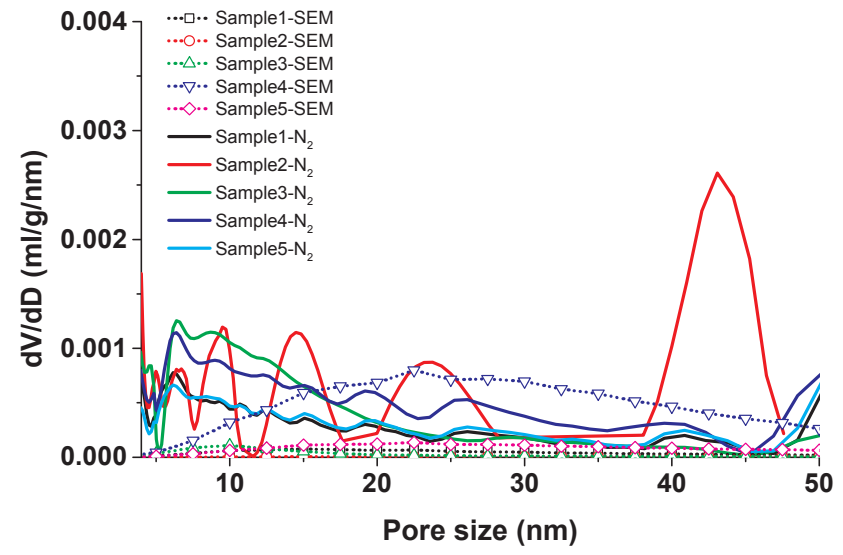

Fig. 14. Pore size distribution of the samples from $4 \mathrm{~nm}$ to $50 \mathrm{~nm}$ measured by gas adsorption and SEM.

As shown in Fig. 17, in the calculation of pore volume, gas adsorption method can obtain the pores connected to the boundary, while the isolated pores inside the sample cannot be measured. Due to the low porosity and low permeability characteristics of the shale itself, there are a large number of isolated pores. SEM can measure the isolated pores but the pores below its resolution will not be detected.

Some conclusions can be drawn: (1) Due to the difference in the pore size definitions of gas adsorption and SEM, the pore size distributions obtained by the two methods are not comparable. Gas adsorption subdivides irregular pores to a series of small pores, but it has a relatively low precision and narrow range in measuring macropores. SEM can measure pores from $50 \mathrm{~nm}$ to $10 \mu \mathrm{m}$ or more, while it generally regards an irregular pore as a simple equivalent big pore. (2) The total pore volume from gas adsorption is much smaller than from SEM as it cannot measure the isolated pores and its limitation in macropores. (3) For the gas storage space, For the gas storage space, gas adsorption method has a more precise characterization of micropores and macropores, which can more accurately determine the adsorption gas storage space, while SEM can obtain a relatively accurate characterization of macropores which is an important space for free gas. The two measurement methods complement each other and both are important for the assessment of total shale gas storage space.

\section{Gas transport characteristics}

\subsection{Permeability of $O M$}

From Fig. 8, it is obvious that the pore structures of the organic pore types are different, which will bring different flow characteristics in OM. Using the SEM images as the digital image, the 3D blocks of different organic pore types are reconstructed by cross correlation based simulation-three step sampling (CCSIM-TSS) method [18,32], as shown in Fig. 18. After obtaining the 3D structures of the OM blocks, the porenetworks in the $\mathrm{OM}$ blocks are extracted using the $\mathrm{AB}$ (axis \& ball)

Table 2

Comparison the pore parameters obtained by SEM and by gas adsorption.

\begin{tabular}{|c|c|c|c|c|c|c|c|c|}
\hline \multirow[t]{2}{*}{ Shale sample } & \multicolumn{4}{|l|}{ SEM } & \multicolumn{4}{|l|}{$\mathrm{N}_{2}+\mathrm{CO}_{2}$ adsorption } \\
\hline & $\begin{array}{l}\text { Surface } \\
\text { porosity }\end{array}$ & $\begin{array}{l}\text { Total pore } \\
\text { volume }(\mathrm{ml} / \mathrm{g})\end{array}$ & $\begin{array}{l}\text { Specific surface } \\
\text { area }\left(\mathrm{m}^{2} / \mathrm{g}\right)\end{array}$ & $\begin{array}{l}\text { Average pore size } \\
\text { (nm) }\end{array}$ & $\begin{array}{l}\text { Micropore volume } \\
(\mathrm{ml} / \mathrm{g})\end{array}$ & $\begin{array}{l}\text { Total pore } \\
\text { volume }(\mathrm{ml} / \mathrm{g})\end{array}$ & $\begin{array}{l}\text { Specific surface } \\
\text { area }\left(\mathrm{m}^{2} / \mathrm{g}\right)\end{array}$ & $\begin{array}{l}\text { Average pore size } \\
\text { (nm) }\end{array}$ \\
\hline Sample 1 & $1.7 \%$ & 0.5139 & 3.9 & 24 & 0.0147 & 0.0283 & 46.6 & 12 \\
\hline Sample 2 & $0.9 \%$ & 0.3026 & 0.8 & 54 & 0.0064 & 0.0205 & 26.9 & 5 \\
\hline Sample 3 & $0.5 \%$ & 0.1962 & 1.2 & 14 & 0.0148 & 0.0319 & 51.0 & 6 \\
\hline Sample 4 & $2.5 \%$ & 0.6328 & 2.6 & 32 & 0.0142 & 0.0373 & 50.5 & 6 \\
\hline Sample 5 & $0.8 \%$ & 0.3765 & 0.8 & 36 & 0.0049 & 0.0188 & 23.5 & 8 \\
\hline
\end{tabular}




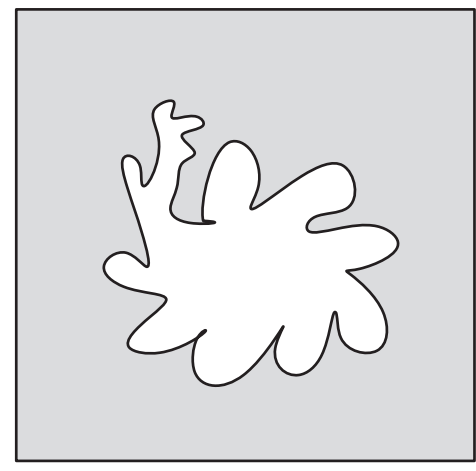

Pore space

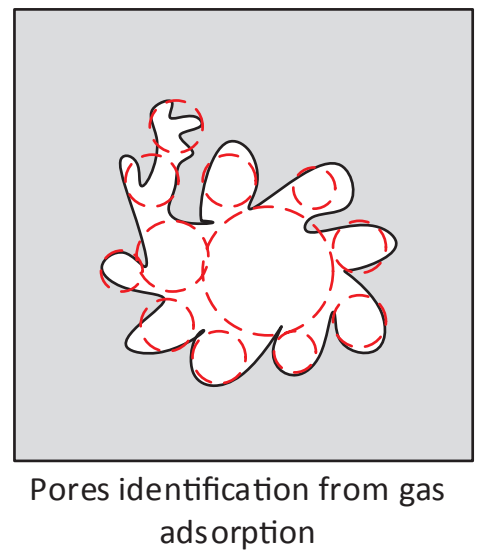

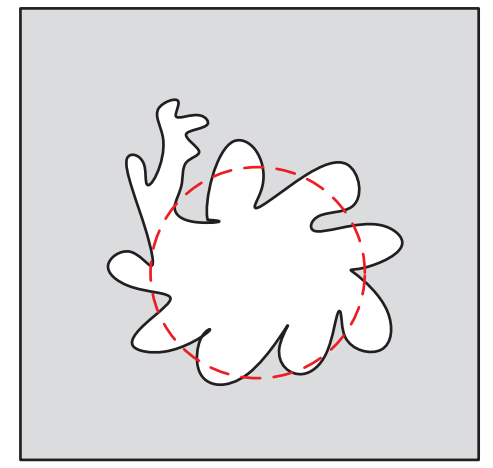

Pores identification from SEM

Fig. 15. Comparison of the pore identification from SEM and gas adsorption.

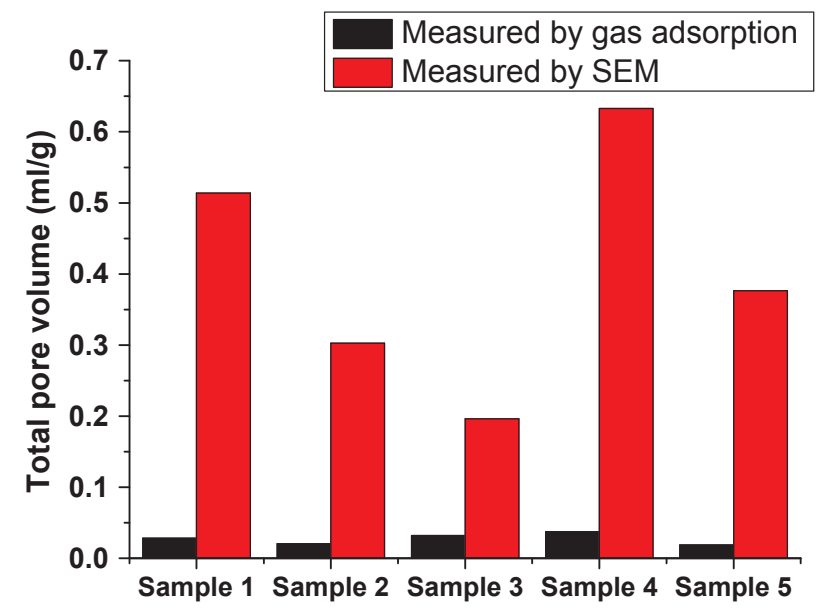

Fig. 16. Comparison of the total pore volumes obtained by SEM and gas adsorption.

algorithm [26]. Then, the characteristic parameters of the OM blocks are obtained to get a quantitative result using the method in Jiang et al. [33], as listed in Table 3.

$R_{n t}$ and $R_{a v g}$ are the different average pore radii of the pore network defined as $R_{n t}=\left(\frac{1}{N} \sum_{i=1}^{N}\left(\frac{1}{r_{i}}\right)^{D_{f}-3}\right)^{-\frac{1}{D_{f}-3}}$ and $R_{\text {avg }}=\left(\frac{1}{N} \sum_{i=1}^{N} \frac{1}{r_{i}}\right)^{-1}$, where $N$ is the number of the throats, $r_{i}$ is the radius of throat $i$. $\Phi_{f}$ is flowing porosity, defined as the ratio of the void volume with flux magnitudes larger than 0 to the total volume. $D_{f}$ is the surface fractal dimension of OM block. $\tau$ is tortuosity. $K_{d, o}$ is the absolute permeability of OM.
Table 3 indicated the differences of those organic pore types are considerable. Sample 1 has the most complex OM constituents, with the Darcy permeability ranges from $0.3 \mathrm{nD}$ to $29.9 \mathrm{nD}$. For Sample 3, type 1 is dominant and has a high flow porosity and Darcy permeability while type 2 is compact. In such cases, FIB-SEM is not a good choice for the representative size as it is hard to be sampled and get all those OM types which will induce errors for $\mathrm{OM}$ characterization, and the 3D reconstruction method using SEM image has a more extensive application in the situation. The characteristic parameters of all those OM types have much difference, expect $R_{n t}, R_{\text {avg }}$ and $\Phi_{f}$ of type 2 in Sample 1, type 1 in Sample 2 and type 1 in Sample 3 are similar, with the values of about $4 \mathrm{~nm}, 4 \mathrm{~nm}$, and $0.5 \%$. Results show that the Darcy permeability of all the organic pore types of those samples are quite different which ranges from $0.3 \mathrm{nD}$ to $366.4 \mathrm{nD}$. Flow porosity ranges from 0.001 to 0.03 , tortuosity range from 1.23 to 3.82 .

Previous works [2,3] have shown that the spatial distribution of OMs has little influence on shale permeability, while the OM content is important. In each sample, the different OM types are adopted to generate an integrated block considering their percentages as Cao et al. $[2,3]$. The integrated block consists of elements standing for different OM types with a random spatial distribution, and then its permeability is calculated using finite volume method with a Dirichlet pressure boundary. The apparent permeability of the integrated $\mathrm{OM}$ is calculated, as shown in Fig. 19. The permeability of the integrated OMs can be regarded as a comprehensive assessment parameter of the OMs in shale. All the integrated OMs of those samples have a non-Darcy effect that apparent permeability decreases as gas pressure increases. Among them, the integrated OM in Sample 4 has the highest permeability, while the apparent permeability of intergrated OM of Sample 1 is the lowest. OMs in Sample 1 has a similar effect on permeability as Sample

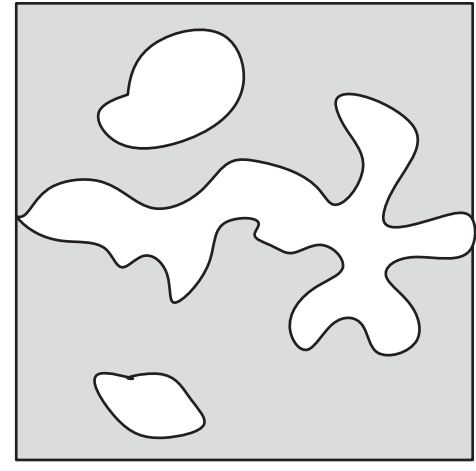

Pore space

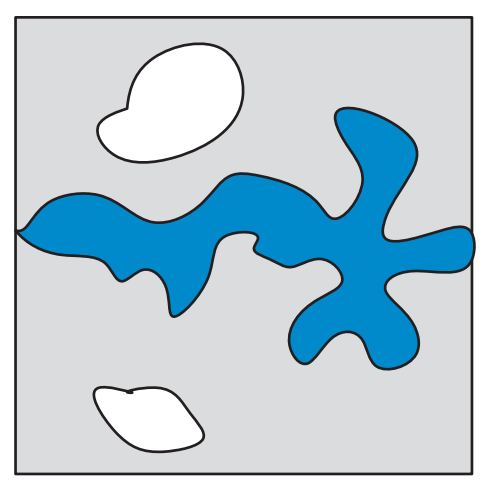

Pore regions from gas adsorption

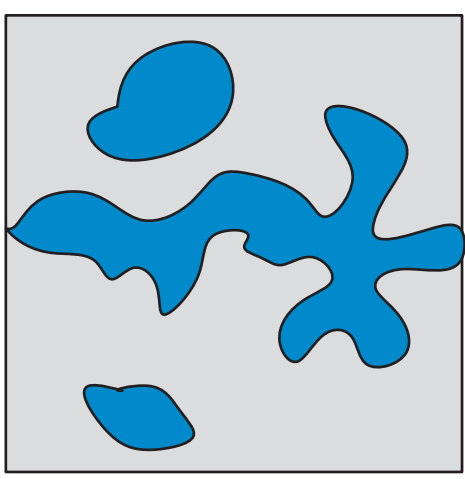

Pore regions from SEM

Fig. 17. Comparison of the pore regions from SEM and gas adsorption. 


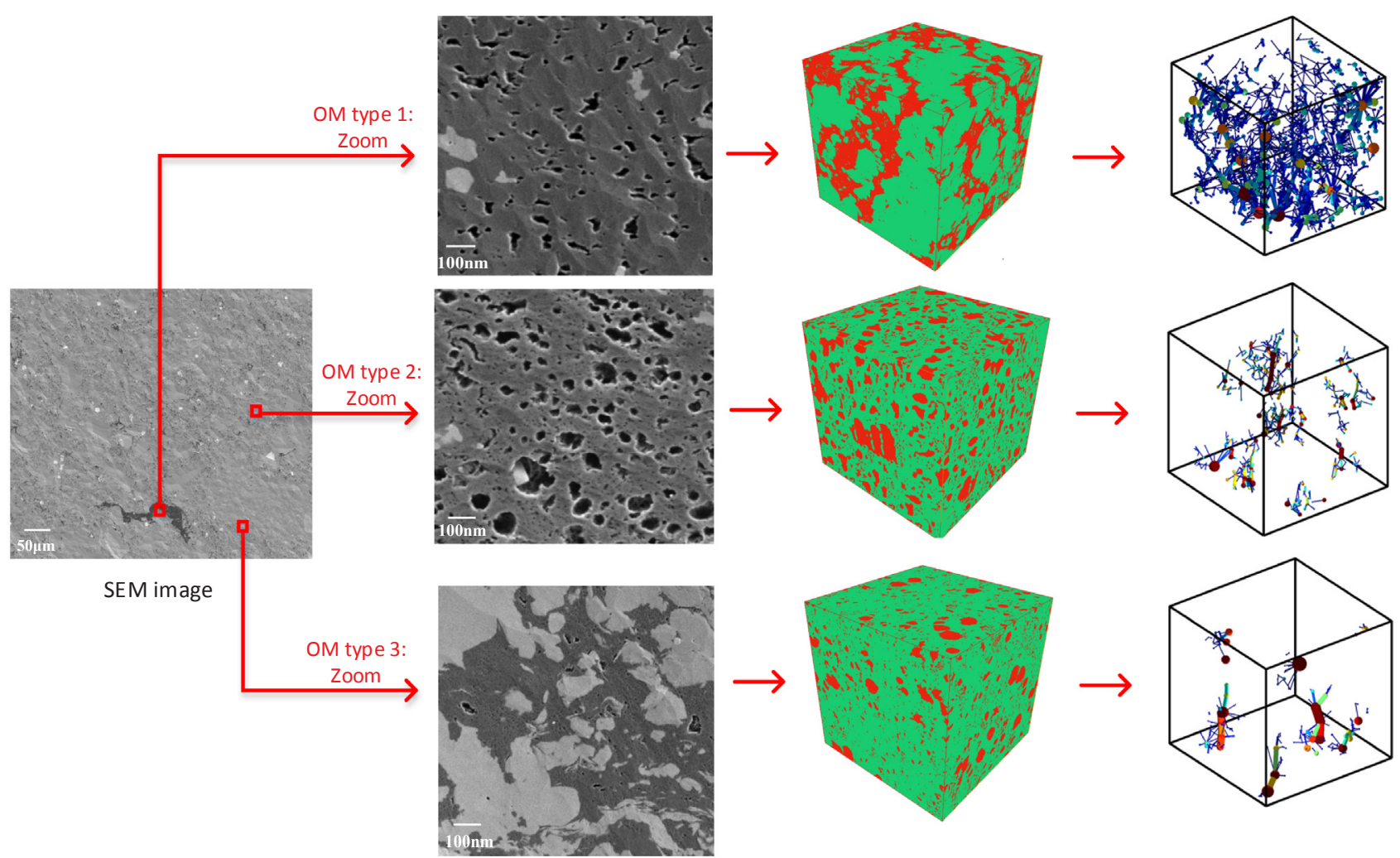

Fig. 18. 3D pore structures of different OM types in Sample 1 using reconstruction from SEM image.

Table 3

Characteristic parameters of OM.

\begin{tabular}{|c|c|c|c|c|c|c|c|c|}
\hline Shale sample & OM type No. & Percentages & $R_{n t}(\mathrm{~nm})$ & $R_{\text {avg }}(\mathrm{nm})$ & $\Phi_{f}$ & $\tau$ & $D_{f}$ & $K_{d, o}(\mathrm{nD})$ \\
\hline \multirow[t]{3}{*}{ Sample 1} & 1 & $20 \%$ & 4.9 & 4.0 & 0.010 & 1.47 & 2.39 & 29.9 \\
\hline & 2 & $35 \%$ & 4.1 & 3.7 & 0.005 & 3.82 & 2.56 & 4.0 \\
\hline & 3 & $45 \%$ & 4.0 & 3.4 & 0.001 & 2.98 & 2.44 & 0.3 \\
\hline Sample 2 & 1 & $100 \%$ & 4.5 & 4.0 & 0.004 & 1.23 & 2.97 & 7.3 \\
\hline \multirow[t]{2}{*}{ Sample 3} & 1 & $78 \%$ & 4.0 & 3.7 & 0.004 & 1.41 & 2.58 & 15.8 \\
\hline & 2 & $22 \%$ & 7.2 & 7.1 & 0.001 & 1.30 & 2.32 & 1.9 \\
\hline \multirow[t]{2}{*}{ Sample 4} & 1 & $76 \%$ & 12.5 & 12.45 & 0.030 & 1.64 & 2.01 & 366.4 \\
\hline & 2 & $24 \%$ & 6.46 & 6.35 & 0.010 & 2.18 & 2.09 & 13.1 \\
\hline Sample 5 & 1 & $100 \%$ & 7.67 & 6.87 & 0.004 & 1.36 & 2.61 & 23.7 \\
\hline
\end{tabular}

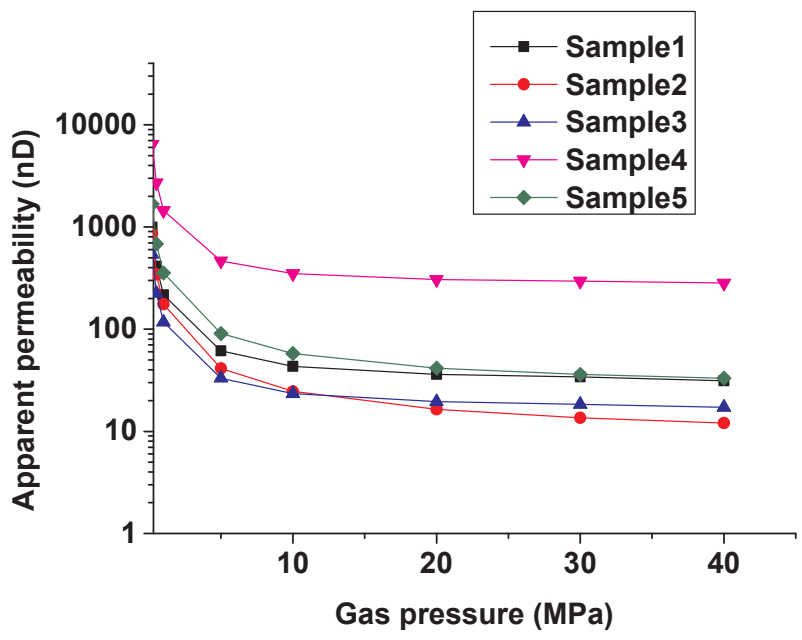

Fig. 19. Apparent permeability of the integrated OMs in those samples.
5. The non-Darcy effect of the OMs in Sample 2 is most significant, due to its smallest average organic pore radius.

\subsection{Permeability of shale cores}

Anisotropic permeability is measured. In this section, we define the subscripts $x, z$ as the directions along the bedding direction and perpendicular to the bedding direction, respectively. The results of $K_{z}$ and $K_{x}$ of the samples are shown in Figs. 20 and 21, respectively.

Fig. 20 shows that the values of $K_{z}$ of the samples are within $160 \mathrm{nD}$, which suggests an extremely low vertical permeability. And the values of $K_{z}$ of those samples are similar, especially for Sample 1 and 2. As the vertical permeability is mainly controlled by the permeability of the shale matrix, according to the lamination property of shale, $K_{z}$ in the same formation is likely to be close. $K_{z}$ is more able to reflect the pore characteristic of shale. For Sample 1 and 2, their locations are adjacent and they have a similar mineral composition, so their $K_{z}$ is similar.

Fig. 21 shows that all the values of $K_{x}$ are bigger than that of $K_{z}$ in the five samples, which shows a general anisotropy. Besides, the values 


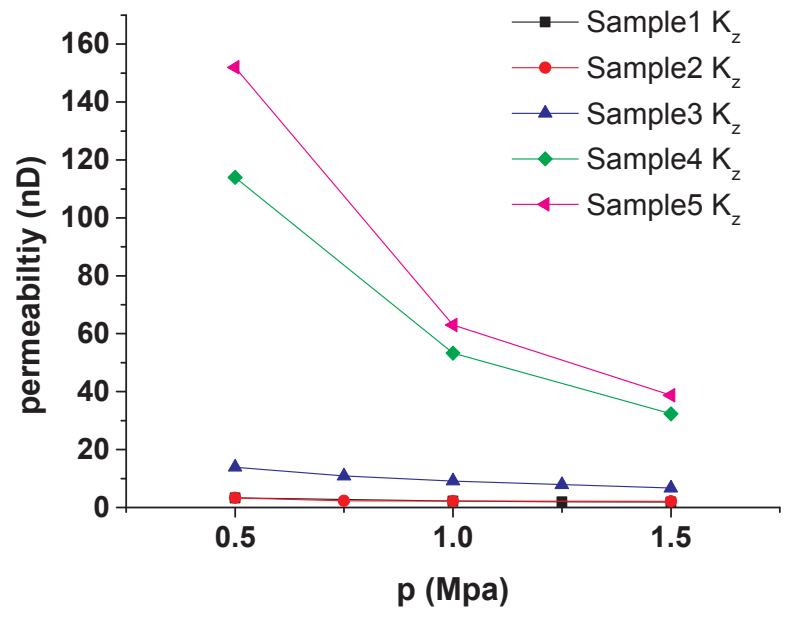

Fig. 20. Measured results of $K_{z}$ of the samples.

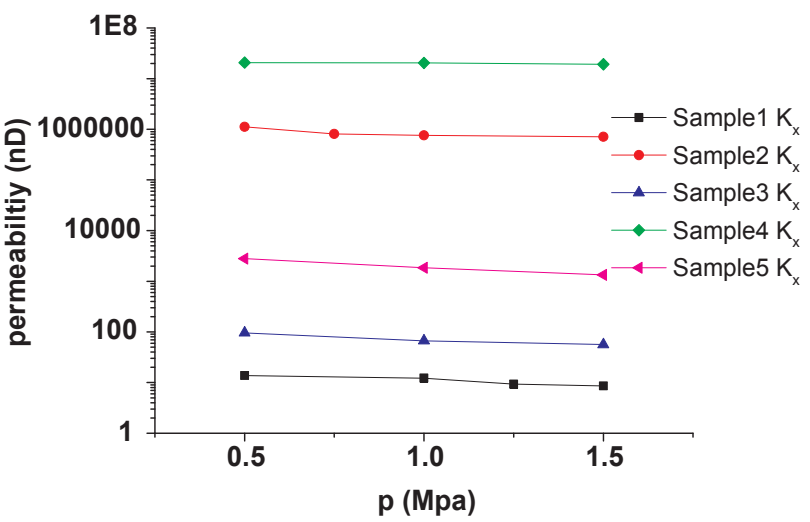

Fig. 21. Measured results of $K_{x}$ of the samples. (Y-axis in log form.)

of $K_{x}$ of the samples are quite different with each other, from $\sim \mathrm{nD}$ to $\sim 10 \mathrm{mD}$ magnitude. Among the samples, $K_{x}$ of Sample 2 and 4 is extremely higher. This difference is mainly caused by the difference of the bedding fractures. Sample 2 and 4 are located in the basin boundary, which are more likely to be influenced by the structural movement and have wider bedding fractures. Results also suggest the the permeability ratio (horizontal vs. vertical) of Sample 2 is also extremely large with the value of about $10^{6}$, which may be induced by the high stress in the reservoir considering its deep burial depth [34].

In addition, all those samples show a significant non-Darcy effect, especially in the direction perpendicular to the bedding under low pressure. The non-Darcy effect of $K_{x}$ is much weaker than than of $K_{z}$, as $K_{z}$ is mainly determined by pore sizes and $K_{x}$ is determined by bedding fractures. Non-Darcy effect will become pronounced with the pressure declining in gas production.

\subsection{Relationships between the permeability of $\mathrm{OM}$ and shale core}

The relationships between the permeability of OMs and shale cores of those samples are analyzed. As the permeability in the direction along the bedding direction of the shale cores will be influenced by bedding fractures. So only the permeability perpendicular to the bedding of the shale core is compared to the permeability of the integrated OMs at the same gas pressure of $1 \mathrm{MPa}$, as shown in Fig. 22. In all those samples, the permeability of OM is higher than that of shale core. As pores in OM form pore networks, resulting in a higher permeability than IOM though the average radius of OM is smaller than IOM. And the porosity of OM is also much higher than IOM. Gas transport is easier in OM. Results also suggest that using only OM permeability for shale gas

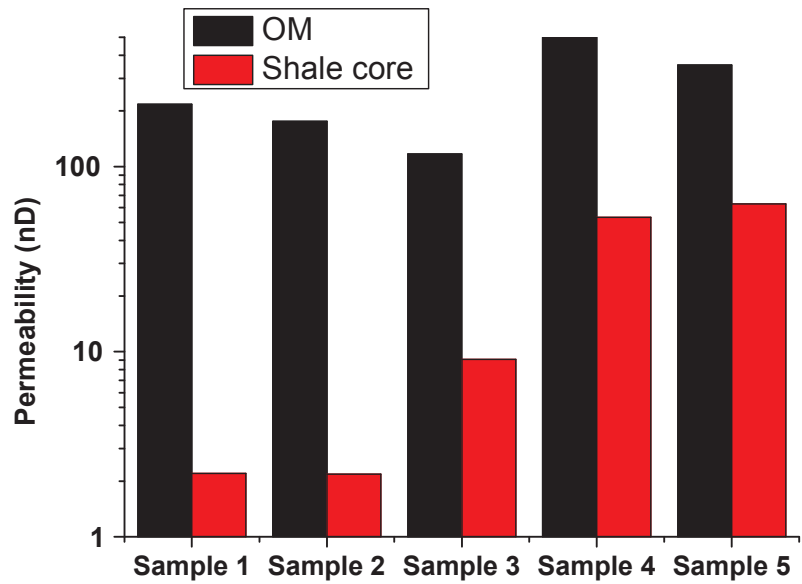

Fig. 22. Comparison of the permeability of OMs and shale cores.

transport is not enough, the coupling effect between OM and IOM is also necessary to be considered.

\section{Discussions}

\subsection{Relationships between pore and gas transport of shale cores}

As gas pressure increase, permeability tends to be absolute or Darcy permeability. Considering the porous media consists of straight pipes, in a Hagen-Poiseuille flow, the absolute permeability can be expressed as $\frac{\phi \bar{r}^{2}}{8}$, where $\phi$ is porosity and $\bar{r}$ is average radius. In this section, He porosity is adopted and the average pore radius from SEM or gas adsorption is employed. The gas pressure and surrounding pressure will affect the permeability. In our measurement, the effective pressure is 3.5 MPa, which has a weak compressibility effect. From Fig. 20, it is obvious that permeability changes rapidly in the low pressure than $1 \mathrm{MPa}$, but then it will tend to be the Darcy's permeability. Using the permeability of shale core at $1.5 \mathrm{MPa}$, the relationships between pore and gas transport are analyzed. Excluding the influence of the bedding fracture, only the permeability perpendicular to the bedding direction is studied here, as show in Fig. 23. Fig. 23 shows that there is a week correlation between $K_{z}$ and $\phi \bar{r}^{2}$ of those samples. But the linear correlation is not significant here, which suggests that the permeability is not simply controlled by porosity and average pore radius, while it is closely related to the pore size distribution, tortuosity and pore structure.

\subsection{Comparisons of different samples}

A comprehensive comparison of different samples is conducted in this section. As multiscale measurements and calculations have been implemented, the pore properties and transport characteristics of those samples are depicted. Among those samples, Sample 3 and Sample 4 are with high quality for gas production. Sample 3 has a buried depth of about $3700 \mathrm{~m}$ which brings high gas pressure, and has high porosity, high OM content and high Langmuir volume. So Sample 3 will have a high gas content. The only deficiency of Sample 3 is its low permeability with the values within $100 \mathrm{nD}$, but this can be improved as it is easy to be hydraulic fractured considering its high quartz content of $64 \%$. Sample 4 also has high porosity, high OM content and high Langmuir volume. Differ from Sample 3, both the permeability of OM and matrix in Sample 4 are much higher than other samples, which will greatly benefit its exploitation. Moreover, though Sample 4 and Sample 5 are close in the same well, their gas storage and transport characteristics are with much difference, especially in their OM contents and pore volumes. Sample 5 has much carbonate but few organic matters. This will increase the requirements for accurate target layer positioning and drilling. 


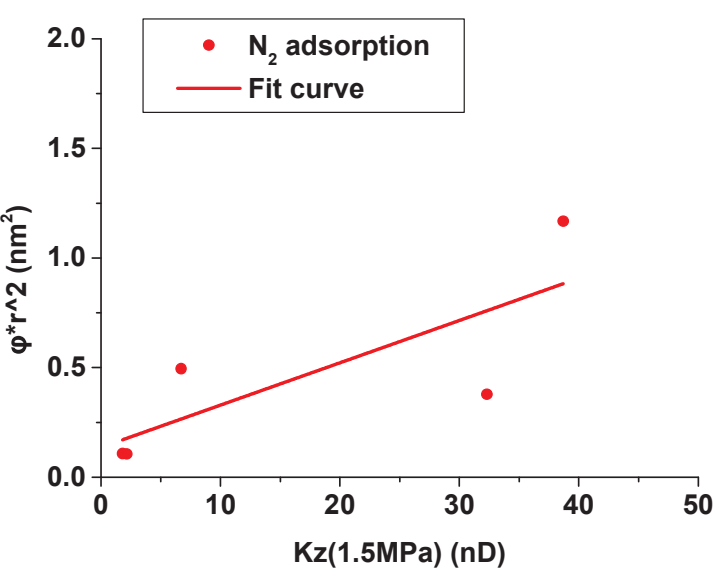

(a)

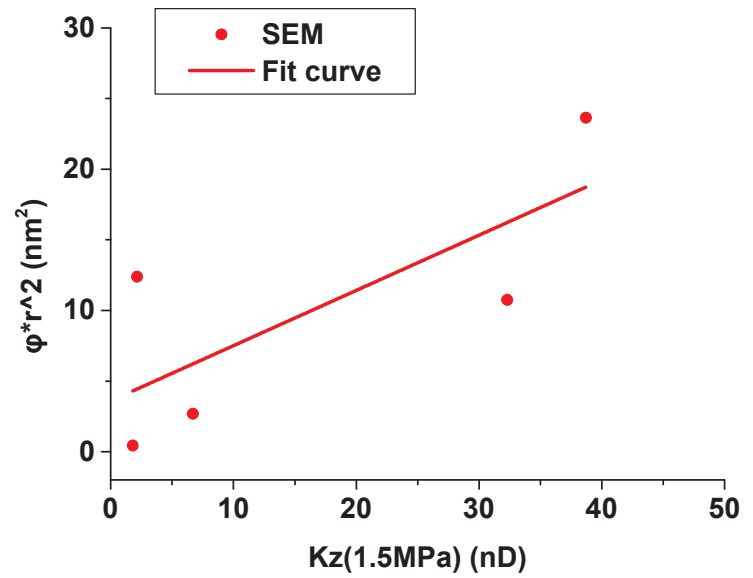

(b)

Fig. 23. Relationships between pore and gas transport of shale cores.

\section{Conclusions}

The development of modern high precision imaging techniques has provided an opportunity to investigate the complex pore structures and gas transport in such ultra-tight porous media as organic-rich shale. In this study, an image-based analysis method along with lots of experiments provides insights into the fine analysis of shale core. Five samples of the same formation (Long $1_{1}$ sub-members of Longmaxi Formation) from different wells are compared. Their pore structures, porosity, adsorption and anisotropic permeability are analyzed by means of the combination of various advanced imaging techniques and experiments. The analysis of the results leads to the following conclusions:

- All samples except Sample 2 are quartz rich. And Sample 1, 2 and 4 are also enriched in Clay. The quartz contents vary from $17 \%$ to $64 \%$.

- The main parts of the inorganic pores are mesopores. There also exists some macropores in IOM even larger than $500 \mathrm{~nm}$. Results show that the Darcy permeability of all the organic pore types of those samples ranges from $0.3 \mathrm{nD}$ to $366.4 \mathrm{nD}$. And the organic pore size distributions tend to be lognormal with the peak pore size from $10 \mathrm{~nm}$ to $30 \mathrm{~nm}$.

- The total pore volume obtained by SEM is found to be several times to several tens of times larger than that obtained by gas adsorption method. For the gas storage space, gas adsorption method has a more precise characterization of micropores and macropores, which can more accurately determine the adsorption gas storage space, while SEM can obtain a relatively accurate characterization of macropores which is an important space for free gas.

- The values of $K_{z}$ of the samples are within $160 \mathrm{nD}$, which suggests an extremely low vertical permeability. The values of $K_{x}$ of the samples are quite different, from $\sim \mathrm{nD}$ to $\sim 10 \mathrm{mD}$ magnitude. The permeability of shale core is strongly anisotropic. In addition, all those samples show a significant non-Darcy effect, especially in the direction perpendicular to the bedding under low pressure.

- Among those samples, Sample 3 and Sample 4 are with high quality for gas production considering their high porosity, high clay contents, high OM contents and high Langmuir volumes.

\section{Acknowledgments}

This work is supported by the National Natural Science Foundation of China (Grant No. 41690132, 41872163 and 41574129), the Strategic Priority Research Program of the Chinese Academy of Sciences (Grant No. XDA14010304), and the Major National Science and Technology
Special Program of China (Grant No. 2017ZX05037-001).

\section{References}

[1] Song W, Yao J, Li Y, Sun H, Zhang L, Yang Y, et al. Apparent gas permeability in an organic-rich shale reservoir. Fuel 2016;181:973-84.

[2] Cao G, Lin M, Jiang W, Li H, Yi Z, Wu C. A 3D coupled model of organic matter and inorganic matrix for calculating the permeability of shale. Fuel 2017;204:129-43.

[3] Cao G, Lin M, Jiang W, Zhao W, Ji L, Li C, et al. A statistical-coupled model for organic-rich shale gas transport. J Petrol Sci Eng 2018;169:167-83.

[4] Curtis JB. Fractured shale-gas systems. AAPG Bull 2002;86:1921-38.

[5] Yang R, He S, Hu Q, Sun M, Hu D, Yi J. Applying SANS technique to characterize nano-scale pore structure of Longmaxi shale, Sichuan Basin (China). Fuel 2017;197:91-9.

[6] Rouquerol J, Avnir D, Fairbridge CW, Everett DH, Haynes JM, Pernicone N, et al. Recommendations for the characterization of porous solids (Technical Report). Pure Appl Chem 1994;66:1739-58.

[7] Xiong F, Jiang Z, Li P, Wang X, Bi H, Li Y, et al. Pore structure of transitional shales in the Ordos Basin, NW China: effects of composition on gas storage capacity. Fue 2017;206:504-15.

[8] Ross DJK, Bustin RM. The importance of shale composition and pore structure upon gas storage potential of shale gas reservoirs. Mar Petrol Geol 2009;26:916-27.

[9] Yan B, Mi L, Wang Y, Tang H, An C, Killough JE. Multi-porosity multi-physics compositional simulation for gas storage and transport in highly heterogeneous shales. J Petrol Sci Eng 2018;160:498-509.

[10] Javadpour F. Nanopores and apparent permeability of gas flow in mudrocks (shales and siltstone). J Can Petrol Technol 2009;48:16-21.

[11] Tian H, Guo GJ, Geng M, Zhang Z, Zhang M, Gao K. Effects of gas reservoir configuration and pore radius on shale gas nanoflow: a molecular dynamics study. J Chem Phys 2018;148:204703.

[12] Darabi H, Ettehad A, Javadpour F, Sepehrnoori K. Gas flow in ultra-tight shale strata. J Fluid Mech 2012;710:641-58.

[13] Shen W, Li X, Xu Y, Sun Y, Huang W. Gas flow behavior of nanoscale pores in shale gas reservoirs. Energies 2017;10:751.

[14] Singh H, Javadpour F. Langmuir slip-Langmuir sorption permeability model of shale. Fuel 2016;164:28-37.

[15] Pan Z, Connell LD. Reservoir simulation of free and adsorbed gas production from shale. J Nat Gas Sci Eng 2015;22:359-70.

[16] Pan Z, Ma Y, Connell LD, Down DI, Camilleri M. Measuring anisotropic permeability using a cubic shale sample in a triaxial cell. J Nat Gas Sci Eng 2015;26:336-44

[17] Ren Y, Guo X, Xie C, Wu H. Experimental study on gas slippage of marine shale in Southern China. Petroleum 2016;2:171-6.

[18] Ji L, Lin M, Jiang W, Cao G. A hybrid method for reconstruction of three-dimensional heterogeneous porous media from two-dimensional images. J Asian Earth Sci 2018.

[19] Saraji S, Piri M. The representative sample size in shale oil rocks and nano-scale characterization of transport properties. Int J Coal Geol 2015;146:42-54.

[20] Zhou S, Yan G, Xue H, Guo W, Li X. 2D and 3D nanopore characterization of gas shale in Longmaxi formation based on FIB-SEM. Mar Petrol Geol 2016;73:174-80.

[21] Wu T, Li X, Zhao J, Zhang D. Multiscale pore structure and its effect on gas transport in organic-rich shale. Water Resour Res 2017;53:5438-50.

[22] Wang Q, Lu H, Wang T, Liu D, Peng PA, Zhan X, et al. Pore characterization of Lower Silurian shale gas reservoirs in the Middle Yangtze region, central China. Mar Petrol Geol 2018;89:14-26.

[23] Feng W, Wang F, Guan J, Zhou J, Wei F, Dong W, et al. Geologic structure controls on initial productions of lower Silurian Longmaxi shale in south China. Mar Petrol Geol 2018;91:163-78. 
[24] Zou C, Dong D, Wang Y, Xinjing LI, Huang J, Wang S, et al. Shale gas in China: characteristics, challenges and prospects (II). Petrol Explor Dev Online 2015;42:753-67.

[25] Liang D, Guo T, Bian L, Chen J, Zhao Z. Some progresses on studies of hydrocarbon generation and accumulation in marine sedimentary regions, Southern China (Part 3): controlling factors on the sedimentary facies and development of Palaeozoic marine source rocks. Mar Origin Petrol Geol 2009.

[26] Zhang M, Tang Q, Cao C, Lv Z, Zhang T, Zhang D, et al. Molecular and carbon isotopic variation in 3.5 years shale gas production from Longmaxi Formation in Sichuan Basin, China. Mar Petrol Geol 2018;89:27-37.

[27] Liang D, Guo T, Chen J. Some progresses on studies of hydrocarbon generation and accumulation in marine sedimentary regions, southern China (Part 1): distribution of four suits of regional marine source rocks. Mar Origin Petrol Geol 2008.

[28] Chen L, Lu Y, Jiang S, Li J, Guo T, Luo C. Heterogeneity of the Lower Silurian Longmaxi marine shale in the southeast Sichuan Basin of China. Mar Petrol Geol 2015;65:232-46.
[29] Li C, Lin M, Ji L, Jiang W, Cao G. Investigation of intermingled fractal model for organic-rich shale. Energy Fuels 2017;31:8896-909.

[30] Chalmers GRL, Ross DJK, Bustin RM. Geological controls on matrix permeability of Devonian Gas Shales in the Horn River and Liard basins, northeastern British Columbia, Canada. Int J Coal Geol 2012;103:120-31.

[31] Curtis ME, Cardott BJ, Sondergeld CH, Rai CS. Development of organic porosity in the Woodford Shale with increasing thermal maturity. Int J Coal Geol 2012;103:26-31.

[32] Ji L, Lin M, Jiang W, Chenjie W. An improved method for reconstructing the digital core model of heterogeneous porous media. Transp Porous Media 2018;121:389-406.

[33] Jiang W, Lin M, Yi Z, Li H, Wu S. Parameter determination using 3D FIB-SEM images for development of effective model of shale gas flow in nanoscale pore clusters. Transp Porous Media 2017;117:5-25.

[34] Adams AL, Germaine JT, Flemings PB, Day-Stirrat RJ. Stress induced permeability anisotropy of resedimented Boston blue clay. Water Resour Res 2013;49:6561-71. 